\title{
Effects of Fuel-injection Parameters on Performance and Exhaust Emissions in a Diesel Engine Equipped with Dual-injector System
}

\section{AUTHOR(S):}

Horibe, Naoto; Egoshi, Kenta; Hirayama, Kazuki; Imanishi, Ryota; Kuwabara, Hiroki; Kawanabe, Hiroshi; Ishiyama, Takuji

\section{CITATION:}

Horibe, Naoto ...[et al]. Effects of Fuel-injection Parameters on Performance and Exhaust Emissions in a Diesel Engine Equipped with Dual-injector System. The international symposium on diagnostics and modeling of combustion in internal combustion engines 2017, 2017.9: B203.

\section{ISSUE DATE:}

2017

URL:

http://hdl.handle.net/2433/237653

\section{RIGHT:}

(c) 2017 The Japan Society of Mechanical Engineers; この論文は出版社 版でありません。引用の際には出版社版をご確認ご利用ください。; This is not the published version. Please cite only the published version. 


\title{
Effects of Fuel-injection Parameters on Performance and Exhaust Emissions in a Diesel Engine Equipped with Dual-injector System
}

\author{
*Naoto Horibe, Kenta Egoshi, Kazuki Hirayama, Ryota Imanishi, Hiroki Kuwabara, \\ Hiroshi Kawanabe, and Takuji Ishiyama
}

Graduate School of Energy Science, Kyoto University

Yoshida-Honmachi, Sakyo-ku, Kyoto 606-8501, Japan

Key Words: Diesel, Dual injector, Injection rate shaping

\begin{abstract}
To examine the feasibility of improving performance through highly flexible fuel injection, a series of experiments were performed using a single-cylinder diesel engine with a dual injector system, which included two sets of common-rail injection systems. The injectors were installed around the center of the cylinder to simulate flexible injection with a single nozzle configuration. This system enabled different injection rates in each injection pulse and a wide dwell range between injection pulses, i.e., even a negative injection dwell could be performed. Experiments with multi-stage injection were conducted using a single-cylinder metal engine, and the behaviors of the sprays and flames were observed in an optically accessible single-cylinder engine with an extended bottom-view piston. Based on a double pilot injection strategy, the effects of the injection pressures, injection timings, and injection quantities of split injection were investigated. The results showed that the dual injector system tended to increase smoke emissions because of a lack of symmetry in the combustion system. The heat release rates were hardly affected by switching from one injector to another for the main injection, whereas the smoke emissions were markedly reduced. A higher main injection pressure with lower pilot injection pressures reduced the smoke emissions with no increase in the $\mathrm{CO}$ emissions. A split-main injection with zero injection dwell increased the thermal efficiency under high injection-pressure conditions. A negative injection dwell markedly increased the smoke emissions.
\end{abstract}

\section{INTRODUCTION}

The common-rail system is widely applied to automotive diesel engines and realizes a multiple injection strategy as a reliable method to control diesel combustion. In addition, it has been reported that a variable injection rate during injection has some positive effects on engine performance such as reducing emissions, improving thermal efficiency, and reducing combustion noise [1-4]. For example, Suzuki et al. [1] used a direct-driven piezo injector and adopted a combined injection strategy that included multiple injections and a variable injection rate. They successfully decreased soot emissions and combustion noise simultaneously. Furthermore, this attempt improved the thermal efficiency while suppressing the combustion noise. Tanabe et al. [2] used dual common-rails with high and low pressure, and Rottmann [3] and Kaster [4] used controlled needle lift. Based on the research of them, boot-shape injection rates simultaneously reduced NOx and PM emissions.

On the other hand, some studies have shown the possibility of improving combustion using a different injection rate for each injection through multiple injectors [5-8]. For example, Merkel et al. [7] simultaneously reduced the NOx and PM emissions by spatially separating the pilot sprays and main sprays with two injectors. However, considering the installation difficulties, multiple injector systems are mainly adopted for large-bore engines. Research on engines for passenger vehicles is difficult to find.

Hence, in this research, in order to clarify the effects of a variable injection rate strategy for a small-size engine, a single cylinder engine with a bore of $85 \mathrm{~mm}$ was used. The variable injection rate was simulated using two closely placed injectors with independent common-rail systems.

This setup allowed a high degree of flexibility for the injection rate and injection patterns. The dual pilot injection strategy was taken as the base strategy. First, the effects of the injection pressure of each injection stage and splitting the main injection were investigated using a metal engine. Moreover, the spray and flame propagating processes were visualized using an optical engine to examine the metal engine results. 
The Ninth International Conference on Modeling and Diagnostics for Advanced Engine Systems (COMODIA 2017), July 25-28, 2017, Okayama, Japan

\section{EXPERIMENTAL SETUP \\ Metal engine experiment}

A schematic of the metal engine system is shown in figure 1 , and the major specifications of the engine are summarized in table 1 . The engine used in this research was a single-cylinder four-stroke diesel engine with a dual injector system (DIS). Figure 2 illustrates the shape of the combustion chamber, which was a toroidal type with a bowl diameter of $60 \mathrm{~mm}$.

Figure 3 shows the spray direction, in which the center lines of two sprays intersect with each other on a circle with a diameter of $55 \mathrm{~mm}$. The intersection points were on the spray center line of a virtual center positioned eight-hole injector with the spray included angle of $156^{\circ}$. The number of nozzle hole were eight because an even number was favorable for symmetric allocation of sprays. And the nozzle-hole diameter of $0.115 \mathrm{~mm}$ was selected so that the fuel flow rate is consistent with that of the original seven-hole nozzle with the diameter of $0.123 \mathrm{~mm}$. Two sets of common-rail systems were utilized, which allowed the injection pressure, timing, and quantity to be changed individually for each injector. Although the injectors were placed as close as possible, because of the engine design restrictions, there was a distance of $13.5 \mathrm{~mm}$ between two injection centers. In order to distinguish these two injectors, the injector on the intake valve side was called $\mathrm{F}$, and that on the exhaust valve side was called $\mathrm{R}$. Several injectors were prepared with the same specification. Based on the injection rate measurement, two injectors with almost the same characteristics were selected for the $\mathrm{F}$ and $\mathrm{R}$ injectors.

Although the original cylinder head had four-valve system, the special head with two intake valves and one exhaust valve was made in order to make space for the installation of two injectors. Based on the previous simulation results, under the operation conditions of this research, removing one of the exhaust valves resulted in no noticeable pumping loss difference.

The main injection quantity was controlled to maintain the gross indicated mean effective pressure (IMEP, excluding intake and exhaust strokes) at $390 \pm 2 \mathrm{kPa}$, which corresponded to a typical low-load condition for a passenger car while the rotation speed was 1,500 rpm. Hence, the total injection quantity was $12.1-13.1 \mathrm{~mm}^{3} /$ cycle. JIS No. 2 diesel fuel with a cetane number of 55 and fuel density of $819.6 \mathrm{~kg} / \mathrm{m}^{3}\left(30^{\circ} \mathrm{C}\right)$ was used. The exhaust gas recirculation (EGR) rate was varied in the range of $43.1-49.3 \%$ to maintain the NOx concentration at $54 \pm 2 \mathrm{ppm}$. The fuel temperature at the pump inlet, lubrication oil, and coolant at the inlet were $30{ }^{\circ} \mathrm{C}, 80^{\circ} \mathrm{C}$, and $80^{\circ} \mathrm{C}$, respectively. The intake charge temperature was $50{ }^{\circ} \mathrm{C}$ and the swirl ratio was 1.3 . The intake and exhaust pressures were set at $102 \mathrm{kPa}$ absolute pressure.

The standard injection pattern was two-stage pilot injection combined with the main injection. The injection timings and quantities were set at $-10.0{ }^{\circ}$ ATDC and $1.9 \mathrm{~mm}^{3} /$ cycle for the first pilot injection, and at $-2.75{ }^{\circ} \mathrm{ATDC}$ and $1.6 \mathrm{~mm}^{3} /$ cycle for the second pilot,



Fig. 1 Experimental setup of metal engine

Table 1 Standard specifications of test engine

\begin{tabular}{|c|c|}
\hline Engine type & $\begin{array}{l}\text { Direct-injection diesel engine, } \\
\text { Single-cylinder, Water-cooled }\end{array}$ \\
\hline Bore $\times$ Stroke $[\mathrm{mm}]$ & $85.0 \times 96.9$ \\
\hline Displacement $\left[\mathrm{cm}^{3}\right]$ & 550 \\
\hline Compression ratio & 16.3 \\
\hline Combustion chamber & $\begin{array}{l}\text { Toroidal } \\
\text { (Cavity diameter: } 60 \mathrm{~mm} \text { ) }\end{array}$ \\
\hline Injection system & $\begin{array}{l}\text { Dual injector system } \\
\text { CRs with a piezo injector, } \\
0.115 \mathrm{~mm} \times 8 \text { holes nozzle } \\
(\text { Original injector: } 0.123 \mathrm{~mm} \times \\
7 \text { holes }-156^{\circ} \text { ) }\end{array}$ \\
\hline Aspiration & External supercharging \\
\hline EGR system & Low-pressure loop EGR \\
\hline Valve system & $\begin{array}{l}\text { Intake valve: two } \\
\text { Exhaust valve: one }\end{array}$ \\
\hline
\end{tabular}

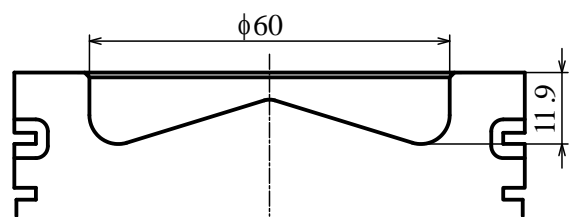

Fig. 2 Shape of combustion chamber



Fig. 3 Arrangement of nozzle hole 
The Ninth International Conference on Modeling and Diagnostics for Advanced Engine Systems (COMODIA 2017), July 25-28, 2017, Okayama, Japan

respectively. The main injection was fixed at $4.0^{\circ} \mathrm{ATDC}$, and was modulated to adjust the IMEP. The effects of the injection pressure and injection pattern, including the injection dwell and injection-quantity ratio of the split main injection, on the engine performance were investigated.

The fueling rates were measured by the radial piston flow meter (Max machinery MODEL 213/295). An engine exhaust gas analyzer (Horiba MEXA1600DEGR) was used to measure the NOx, THC, CO, $\mathrm{CO}_{2}$, and $\mathrm{O}_{2}$ concentration, and the smoke emissions were acquired using a filter-type smoke meter (Avl 415SE). The heat release rates were calculated from the in-cylinder pressure histories (50-cycle average) recorded by a pressure sensor (Kistler 6052A).

\section{Optical engine experiment}

The optical engine specifications are summarized in table 2. The injection system and intake and exhaust system (cam profile, port shape, and number of valves) were identical to those of the metal engine. A Bowditch piston with a diameter of $51.8 \mathrm{~mm}$ was used, and the volume of the piston bowl was the same as that of the metal engine. Because an extended piston was applied, the TDC clearance was increased from $0.7 \mathrm{~mm}$ to 0.9 $\mathrm{mm}$ for safety reasons. The compression ratio was 15.4 , which was lower compared to the metal engine because of the change of the TDC clearance and the top ring position. The intake temperature and pressure were controlled using a supercharger, an intercooler, and an electronic heater. Nitrogen was mixed with the intake charge to reduce the oxygen concentration to the same as the metal engine conditions. Because the optical engine was slightly different from the metal engine in relation to the compression ratio, and the shape and material of the piston, the intake temperature and pressure were increased to reproduce the heat release rate history of the metal engine. The injection signal settings were same as the metal engine conditions.

The sprays and flames inside the chamber were visualized using a high speed color camera (Photron FASTCAM SA-X2) without optical filters, and a metal halide lamp was used as a light source. All the imaging conditions were basically fixed although the lens aperture was slightly different between the images in "Effect of injection pattern" and "Effect of split condition." The interval of each frame was set to $0.5{ }^{\circ} \mathrm{CA}$, and the exposure time was $40 \mu \mathrm{s}$. The field of vision is illustrated in figure 4 . Fuel was injected in a sequence of seven cycles, and the images of six cycles (excluding for the first cycle) were analyzed.

\section{RESULTS AND DISCUSSIONS Effect of injection pattern}

First, in order to investigate the influence of the choice of injectors, several injection patterns were tested using the metal engine. The injection patterns are shown in figure 5. The first pattern was "FFF," in which only injector F was used. The injection pattern that only used injector R was named "RRR.” In addition, "FFR” means
Table 2 Standard specifications of optical engine

\begin{tabular}{|l|l|}
\hline Engine type & $\begin{array}{l}\text { Direct-injection diesel engine, } \\
\text { Single-cylinder, Water-cooled }\end{array}$ \\
\hline Bore $\times$ Stroke $[\mathrm{mm}]$ & $85.0 \times 96.9$ \\
\hline Compression ratio & 15.4 \\
\hline Piston & $\begin{array}{l}\text { Bottom-view Bowditch type } \\
\text { (Cavity diameter: 51.8 mm) }\end{array}$ \\
\hline Injection system & $\begin{array}{l}\text { Dual injector system } \\
\text { (Same as metal test engine) }\end{array}$ \\
\hline Aspiration & $\begin{array}{l}\text { External supercharging with } \\
\text { supply system of nitrogen }\end{array}$ \\
\hline
\end{tabular}

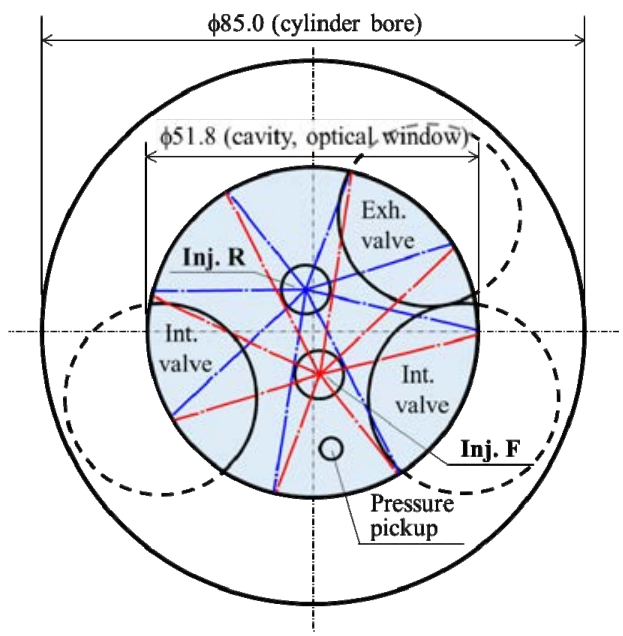

Fig. 4 Field of observation in optical engine

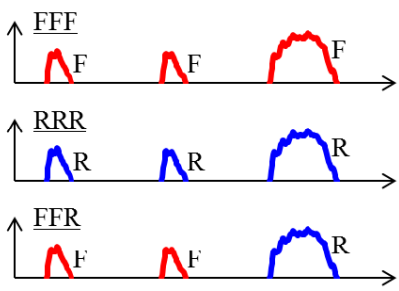

Fig. 5 Injection pattern

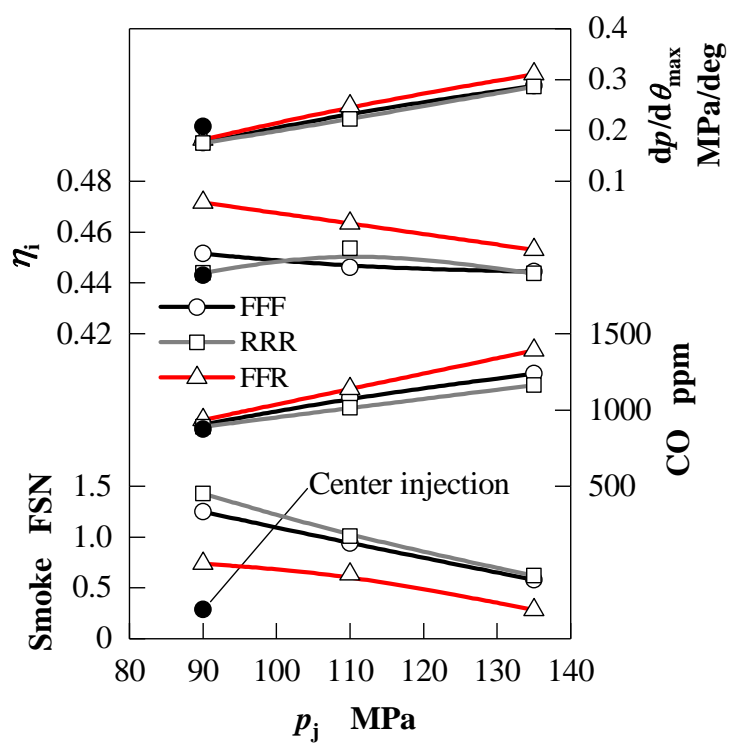

Fig. 6 Effect of injection pattern on engine performance and emissions 
The Ninth International Conference on Modeling and Diagnostics for Advanced Engine Systems (COMODIA 2017), July 25-28, 2017, Okayama, Japan



Fig. 7 Comparison of in-cylinder pressures and heat-release rates of injection patterns

Table 3 Operating conditions of optical engine

\begin{tabular}{|c|c|c|c|c|c|c|c|c|c|}
\hline \multirow{2}{*}{ Inj. pattern } & \multicolumn{2}{|c|}{$1^{\text {st }}$ pilot inj. } & \multicolumn{2}{|c|}{$2^{\text {nd }}$ pilot inj. } & \multicolumn{2}{|c|}{ Main inj. } & $\begin{array}{c}\text { Intake } \\
\text { press. }\end{array}$ & $\begin{array}{c}\text { Intake } \\
\text { temp. }\end{array}$ & $\begin{array}{c}\text { Intake } \\
\mathrm{O}_{2}\end{array}$ \\
\cline { 2 - 10 } & {$\left[{ }^{\circ}\right.$ ATDC] } & {$\left[\mathrm{mm}^{3} /\right.$ cycle $]$} & {$\left[{ }^{\circ}\right.$ ATDC] } & {$\left[\mathrm{mm}^{3} /\right.$ cycle $]$} & {$\left[{ }^{\circ}\right.$ ATDC] } & {$\left[\mathrm{mm}^{3} /\right.$ cycle $]$} & {$[\mathrm{kPa}(\mathrm{a})]$} & {$\left[{ }^{\circ} \mathrm{C}\right]$} & {$[\%]$} \\
\hline \hline FFF & -10.0 & 1.9 & -2.75 & 1.6 & 4.0 & 9.4 & 121 & 52.7 & 16.3 \\
\hline FFR & -10.0 & 1.9 & -2.75 & 1.6 & 4.0 & 8.6 & 121 & 52.2 & 16.2 \\
\hline
\end{tabular}

that injector $\mathrm{F}$ was used for pilot injections and injector $\mathrm{R}$ was used for the main injection.

Figure 6 shows the effects of the injection pattern on the smoke, CO concentration, indicated thermal efficiency $\eta_{\mathrm{i}}$, and maximum pressure rise rate $\mathrm{d} p / \mathrm{d} \theta_{\max }$. The injection pressure $p_{\mathrm{j}}$ was varied from $90 \mathrm{MPa}$ to $135 \mathrm{MPa}$. For comparison, the results of conventional center injection with a nozzle having seven $0.125 \mathrm{~mm}$ orifices are also plotted. All the engine specifications and the experimental conditions of the center injection were same as DIS test conditions except for the nozzle specifications and the nozzle position. The smoke emissions of DIS are higher than that of center injection at the same injection pressure. This problem will be improved in later research. For all of the injection patterns, when the injection pressure is increased, the smoke emissions decrease, the $\mathrm{CO}$ and maximum pressure rise rate increase, and $\eta_{\mathrm{i}}$ decreases.

Focusing on the effect of the injection pattern, the engine performance and emission results are almost the same when using only one injector (FFF, RRR). On the other hand, the FFR pattern increases $\eta_{\mathrm{i}}$ and decreases the smoke emissions. Therefore, it can be inferred that the engine performance and emission differences between FFR and FFF/RRR are not the result of differences in the injectors' characteristics but the result of differences in the air-fuel mixing and combustion process.

A combustion analysis was performed to investigate the cause of this improvement. The histories of in-cylinder pressure $p$, heat release rate $\mathrm{d} Q / \mathrm{d} \theta$, and the injection duration with respect to the crank angle are illustrated in figure 7 . The injection duration was separately measured using an injection rate meter. Compared with center injection, all of the DIS injection patterns show slightly shorter ignition delays for the
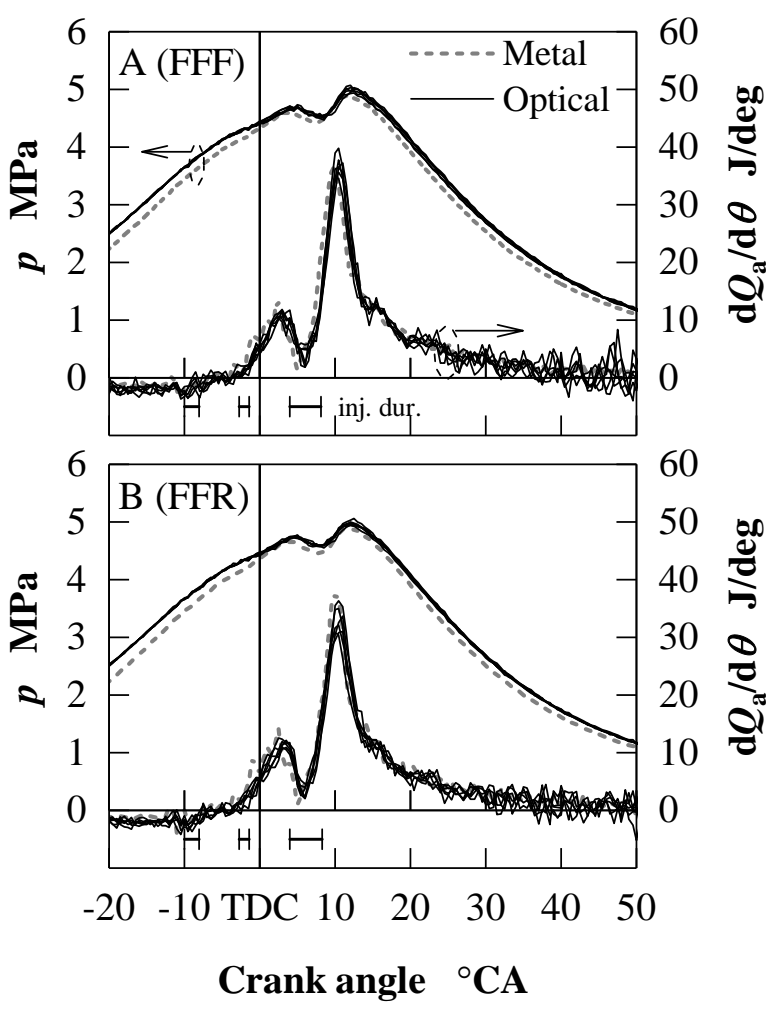

Fig. 8 Comparisons of in-cylinder pressures and apparent heat release rates of optical engine and metal engine

main injection at an injection pressure of $90 \mathrm{MPa}$. At all of the injection pressures, the heat release rate of DIS is not markedly influenced by the injection pattern, but the maximum heat release rate is higher for FFR. It is suggested that the amount of the hot fuel-air mixture from the pilot sprays entrained into the main sprays is 
The Ninth International Conference on Modeling and Diagnostics for Advanced Engine Systems (COMODIA 2017), July 25-28, 2017, Okayama, Japan
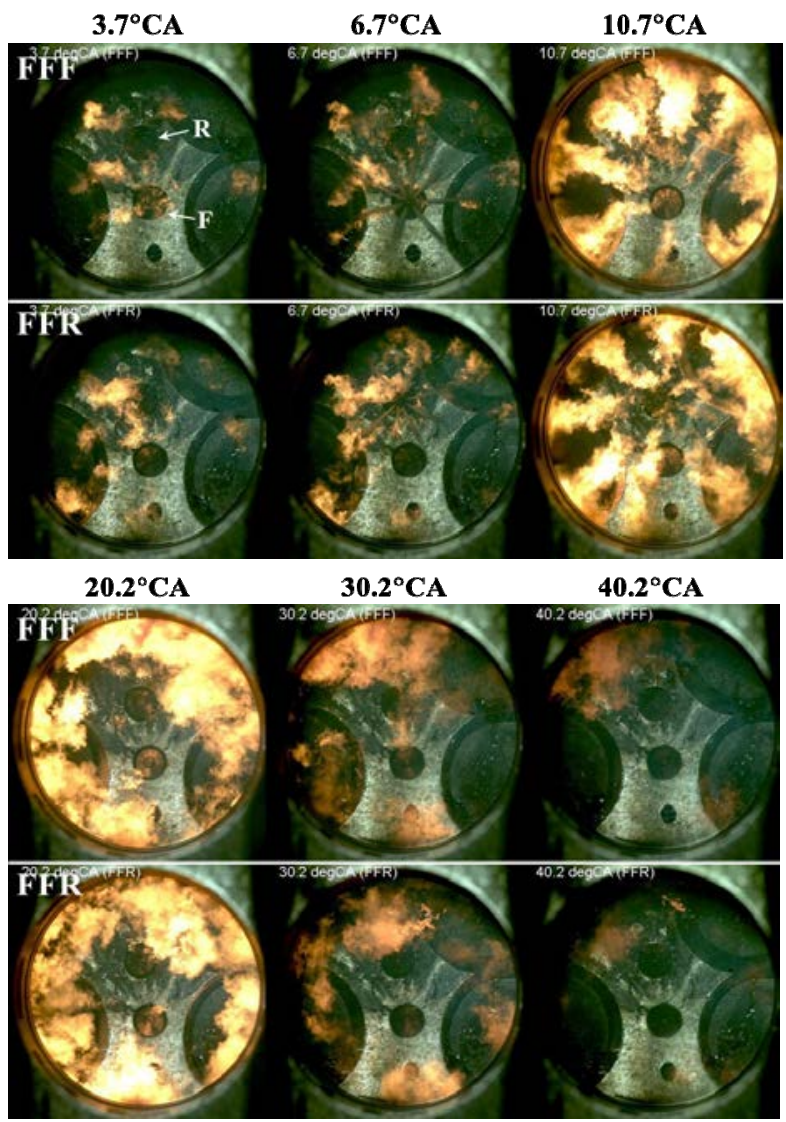

Fig. 9 Comparison of combustion processes of injection patterns FFF and FFR

reduced when the pilot and main injections are from different injectors.

In summary, the smoke emissions increase compared with center injection when using DIS but decrease when adopting injection pattern FFR. Optical experiments were conducted for FFF and FFR to explain the latter result. The operating conditions are listed in table 3 . The in-cylinder pressure $p$ and apparent heat release rate $\mathrm{d} Q_{\mathrm{a}} / \mathrm{d} \theta$ of the metal and optical engines are shown in figure 8 . The value of $\mathrm{d} Q_{\mathrm{a}} / \mathrm{d} \theta$ was calculated by fixing the specific heat ratio at 1.4 . For the metal engine, the average values for 50 cycles are illustrated, and for the optical experiments, all of the values for 6 cycles are shown. Even though the compression ratio of the optical engine was lower than that of the metal engine, the heat release rate could be reproduced by adjusting the intake pressure and temperature. In addition, the cycle-to-cycle variation was small. The coefficients of variation of gross IMEP were $2.2 \%$ and $1.2 \%$ for FFF and FFR respectively.

Figure 9 shows image sequences for representative cycles of FFF and FFR. In the images for $3.7^{\circ}$ ATDC, which is just before the start of the main injection, a larger luminous flame from pilot sprays can be observed in the upper area compared to the bottom area for both FFF and FFR. At $6.7^{\circ}$ ATDC, luminous flames from the main spray appear in the upper area. At $10.7{ }^{\circ}$ ATDC, bright luminous flames are observed in the upper area for

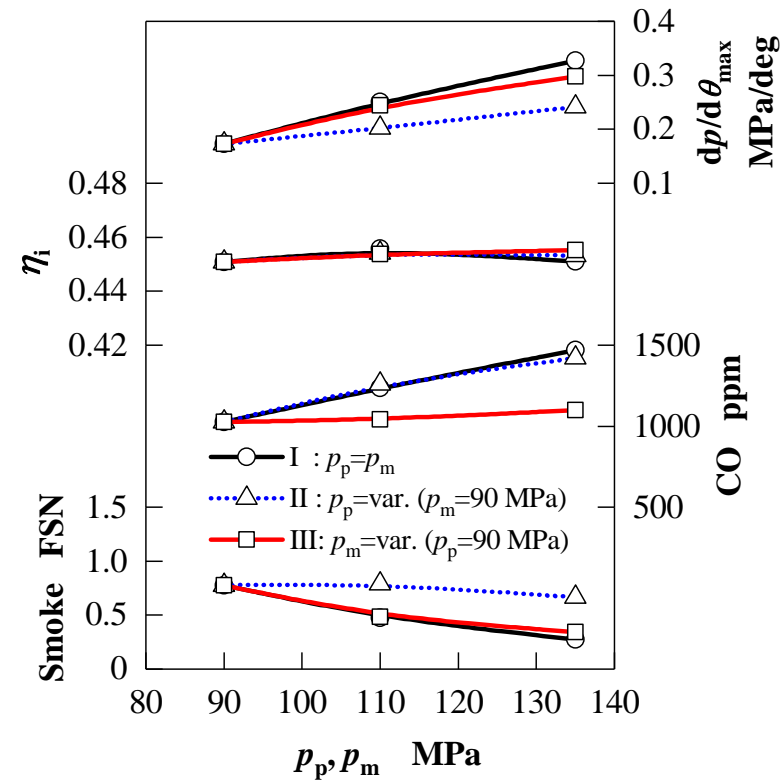

Fig. 10 Effects of pilot-injection pressure and main-injection pressure on engine performance and emissions

FFF. On the other hand, a larger luminous flame appears in the bottom area for FFR compared to FFF. Thus, sprays that have longer paths to the wall show a larger luminous flame, probably because the lower momentum weakens the spread of the sprays after their wall impingement, leading to the formation of rich mixtures.

Based on this assumption, it is theorized that the higher smoke emissions of DIS compared with center injection are caused by the weak impingement. Furthermore, the smaller nozzle orifices of DIS compared to those for center injection would be another reason for the weak impingement.

The smoke of FFR is lower than that for FFF because a large part of the main-spray mixture of FFR is located in the bottom area of the images where the formation of a rich mixture by the pilot spray is mitigated by the shorter distance from the nozzle. Further study is necessary to clarify the mechanism.

\section{Effect of injection pressure}

As previously mentioned, by increasing the injection pressure, the smoke emissions can be decreased, but the CO emissions increase. It is well-known that an overly lean mixture of the pilot injection is one of the causes of $\mathrm{CO}$ emissions [9]. Aiming to solve this trade-off relationship between the smoke and CO emissions, the injection pressures of the pilot injection and main injection were varied independently.

Figure 10 shows the smoke, CO concentration, indicated thermal efficiency $\eta_{\mathrm{i}}$, and maximum pressure rise rate $\mathrm{d} p / \mathrm{d} \theta_{\max }$. Injection pattern FFR was selected for this set of experiments. The same injection pressure was used for every stage of the injection using pattern "I." Main injection pressure $p_{\mathrm{m}}$ was fixed at $90 \mathrm{MPa}$, while pilot injection pressure $p_{\mathrm{p}}$ was varied using pattern "II." In pattern "III," $p_{\mathrm{p}}$ was fixed at $90 \mathrm{MPa}$, while $p_{\mathrm{m}}$ was 
The Ninth International Conference on Modeling and Diagnostics for Advanced Engine Systems (COMODIA 2017), July 25-28, 2017, Okayama, Japan



Fig. 11 Schematic diagram of injection rates for single-main and split-main injection patterns

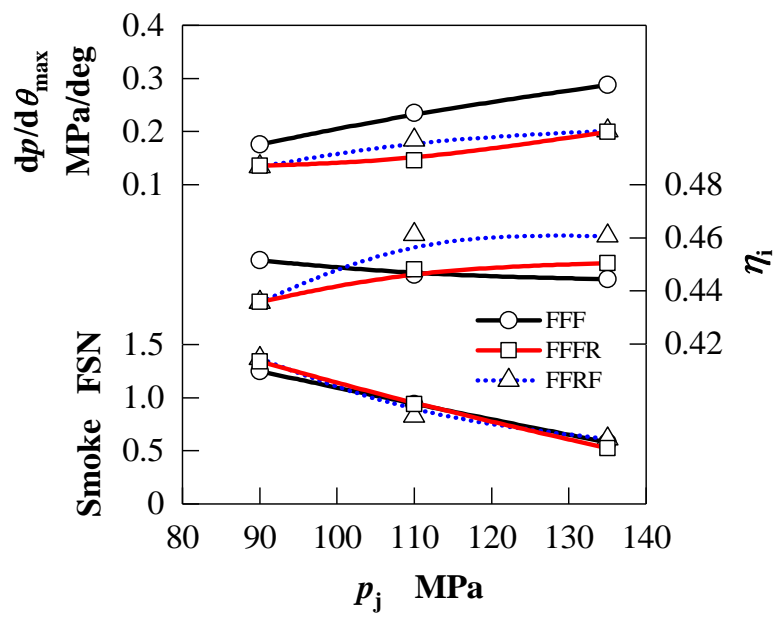

Fig. 12 Effects of split main injection on engine performance and emissions

varied. When changing only the pilot-injection pressure (II), the smoke emissions change slightly, but the CO emissions increase in a way similar to that in the case of pattern I. An increase in the overly lean mixture of the pilot sprays is a cause of the higher CO emissions. On the other hand, when only the main-injection pressure increases (III), the smoke emissions decrease as in pattern I, while the $\mathrm{CO}$ emissions remain unchanged. Thus, using different pressures for the pilot and main injections is effective for exhaust emission control.

\section{Split main injection}

It has been reported that the cooling loss through the wall of a combustion chamber decreases, and hence the thermal efficiency increases, when the spray penetration is suppressed by splitting the main injection [10, 11]. Moreover, because air entrainment is enhanced after the injection process [12], it is expected that the smoke emissions can be reduced by split injection. On the other hand, a longer combustion duration has a negative effect on the thermal efficiency when the injection pressure and/or response of the injection device are restricted. Therefore, we attempted to realize low smoke and high thermal efficiency combustion by splitting the main injection with a zero interval, as shown in figure 11 .

In this section, two injection patterns are introduced. For both patterns, injector $\mathrm{F}$ is responsible for dual pilot injections. The main injection is split into two injections with almost the same fuel mass and no interval. As shown in figure 11, the pattern in which the main

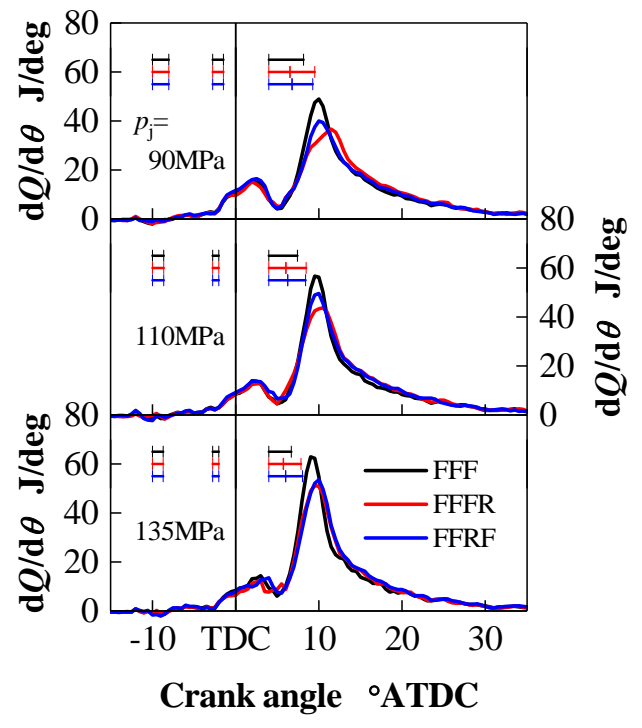

Fig. 13 Comparison of heat-release rates between single and split-main injection conditions

injection is provided by injector $\mathrm{F}$ and then $\mathrm{R}$ is called "FFFR," and that where it is provided by injector $\mathrm{R}$ and then $\mathrm{F}$ is called "FFRF."

If the injection pressure is not changed from the single-main case, the maximum injection rate of the main injections decreases, and the total injection duration increases. Therefore, the effects of the injection pressure were examined with the split-main injection. The same injection pressure was used for the pilot and main injections. The maximum injection rate of the split-main injection with a pressure of $110 \mathrm{MPa}$ was comparable to that of the single-stage main injection with $90 \mathrm{MPa}$. When the injection pressure reached $135 \mathrm{MPa}$, the total duration of the split-main injection was identical to that of the single-stage main injection with $90 \mathrm{MPa}$. The quantity of the first stage of the main injection was fixed at $4.6 \mathrm{~mm}^{3} /$ cycle, while that of second stage was controlled to adjust the IMEP to $390 \mathrm{kPa}$. Consequently, the injection quantity of the second stage of the main injection was $4.4-4.8 \mathrm{~mm}^{3} /$ cycle.

The performance and emission characteristics of the single-stage main injection and split-main injection are shown in figure 12 . The smoke emissions change slightly when the main injection is split with the same injection pressure as in the single-main case (FFF). Splitting the main injection extends injection duration and reduces the average injection rate. It is considered that there was a balance between the smoke decrease effect resulting from the enhancement of air entrainment in the split-main injection and the smoke increase effect of the low injection rate. However, for the case with the same injection duration, FFFR or FFRF with $135 \mathrm{MPa}$ reduces the smoke emissions dramatically without sacrificing the maximum pressure rise rate, and shows a thermal efficiency comparable to FFF with $90 \mathrm{MPa}$.

The thermal efficiency trend is complicated. With the single-stage main injection, the thermal efficiency decreases as the injection pressure increases. On the 
The Ninth International Conference on Modeling and Diagnostics for Advanced Engine Systems (COMODIA 2017), July 25-28, 2017, Okayama, Japan



Fig. 14 Schematic diagram of injection rates for split injection and after-injection patterns

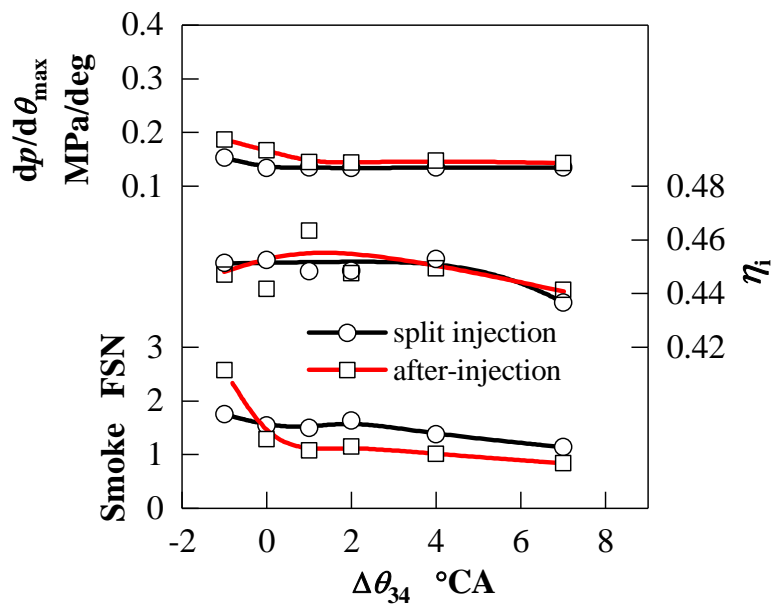

Fig. 15 Effects of split-injection dwell and split distribution of injection quantity on engine performance and emissions

other hand, the thermal efficiency increases as the injection pressure increases when the main injection is split. With injection pressures of $110 \mathrm{MPa}$ and $135 \mathrm{MPa}$, the split-main injection shows higher thermal efficiencies compared to the single-stage main injection. In addition, the maximum pressure rise rates are reduced by splitting the main injection.

Figure 13 shows the heat release rate of each condition shown in figure 12 . For all of the injection pressures, the peak heat release rates decrease, and the heat release rates of the late combustion phase near 15-20 ${ }^{\circ}$ ATDC increase by using DIS. For an injection pressure of $90 \mathrm{MPa}$, the slower combustion of the split-main injection would be a reason for the lower thermal efficiency. However, for $110 \mathrm{MPa}$ and $135 \mathrm{MPa}$, the thermal efficiency trend cannot be explained by the heat release rate. Further study is required to clarify the

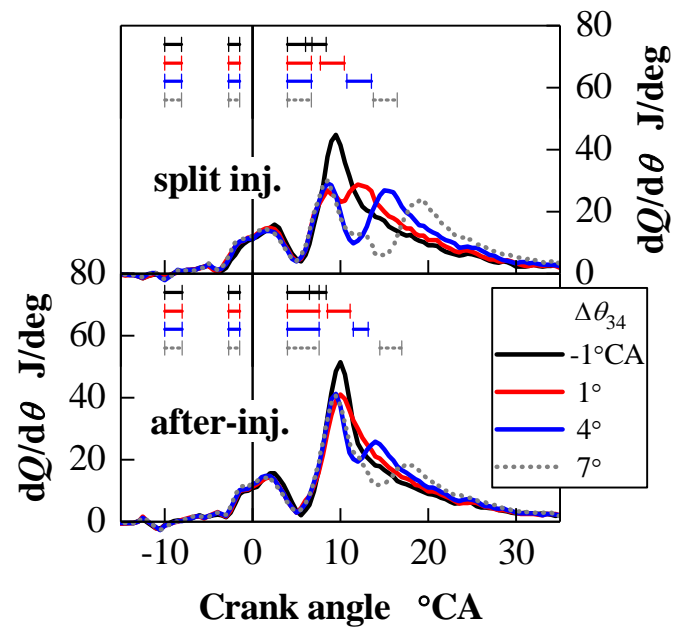

Fig. 16 Effects of split-injection dwell and split ratio of injection quantity on heat-release rate

reason.

\section{Effect of split condition}

To obtain more information on the effect of the splitmain injection, its injection dwell was varied in the range of -1 to $8{ }^{\circ} \mathrm{CA}$. Here, a negative injection dwell indicates that the injection durations overlapped each other. A schematic diagram of the injection rate is given in figure 14. Injection pattern "FFRF" was selected, with an injection pressure of $90 \mathrm{MPa}$. Furthermore, because the second stage of the main injection was expected to have the effect of post injection, the injection quantity of first stage of the main injection was increased to $6.8 \mathrm{~mm}^{3} /$ cycle, while that of the second stage injection was decreased to approximately $2.6 \mathrm{~mm}^{3} /$ cycle. The IMEPs were adjusted by varying the quantity of the second stage of the main injection.

Figure 15 shows the engine performance and emissions against the injection dwell of the split-main injection $\Delta \theta_{34}$. The smoke emissions decrease slightly when the injection interval of the split-main injection increases from $0{ }^{\circ} \mathrm{CA}$. In addition, the smoke emission is lower when the injection quantity of the second stage of the main injection is decreased compared to an equal injection quantity for the first-stage injection (split injection). However, when the injection interval is decreased to $-1{ }^{\circ} \mathrm{CA}$, the smoke emission increases markedly. When the injection interval is extended to $7{ }^{\circ} \mathrm{CA}$, the thermal efficiency decreases. According to the heat release rate illustrated in figure 16 , by extending the injection interval, the phase of the heat release rate is

Table 4 Operating conditions of optical engine for split-main injection

\begin{tabular}{|c|c|c|c|c|c|c|c|c|c|c|c|c|}
\hline \multirow{2}{*}{ Case } & \multirow{2}{*}{$\begin{array}{c}\text { Inj. } \\
\text { pattern }\end{array}$} & \multicolumn{2}{|c|}{$1^{\text {st }}$ pilot inj. } & \multicolumn{2}{|c|}{$2^{\text {nd }}$ pilot inj. } & \multicolumn{2}{|c|}{$1^{\text {st }}$ main inj. } & \multicolumn{2}{|c|}{$2^{\text {nd }}$ main inj. } & $\begin{array}{c}\text { Intake } \\
\text { press. }\end{array}$ & $\begin{array}{c}\text { Intake } \\
\text { temp. }\end{array}$ & $\begin{array}{c}\text { Intake } \\
\mathrm{O}_{2}\end{array}$ \\
\cline { 3 - 15 } & & {$\left[{ }^{\circ}\right.$ ATDC] } & {$\left[\mathrm{mm}^{3} / \mathrm{cycle}\right]$} & {$\left[{ }^{\circ}\right.$ ATDC] } & {$\left[\mathrm{mm}^{3} / \mathrm{cycle}\right]$} & {$\left[{ }^{\circ}\right.$ ATDC] } & {$\left[\mathrm{mm}^{3} / \mathrm{cycle}\right]$} & {$\left[{ }^{\circ}\right.$ ATDC] } & {$\left[\mathrm{mm}^{3} / \mathrm{cycle}\right]$} & {$[\mathrm{kPa}(\mathrm{a})]$} & {$\left[{ }^{\circ} \mathrm{C}\right]$} & {$[\%]$} \\
\hline \hline A & FFRF & -10.0 & 1.9 & -2.75 & 1.6 & 4.0 & 4.6 & 8.0 & 4.8 & 119 & 64.8 & 16.4 \\
\hline B & FFRF & -10.0 & 1.9 & -2.75 & 1.6 & 4.0 & 6.8 & 8.5 & 2.6 & 119 & 63.1 & 16.4 \\
\hline C & FFRF & -10.0 & 1.9 & -2.75 & 1.6 & 4.0 & 6.8 & 6.5 & 2.6 & 119 & 62.2 & 16.0 \\
\hline
\end{tabular}


The Ninth International Conference on Modeling and Diagnostics for Advanced Engine Systems (COMODIA 2017), July 25-28, 2017, Okayama, Japan

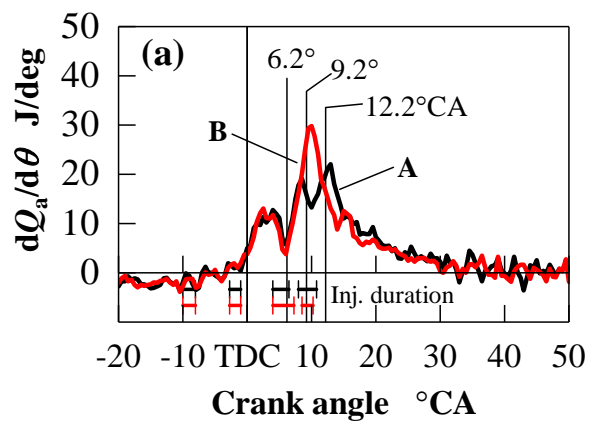

(b)
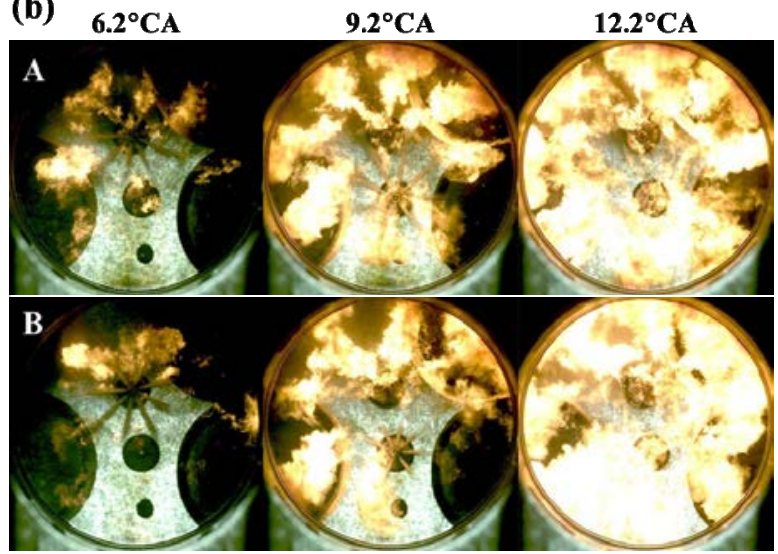

$20.2^{\circ} \mathrm{CA}$ $30.2^{\circ} \mathrm{CA}$ $40.2^{\circ} \mathrm{CA}$

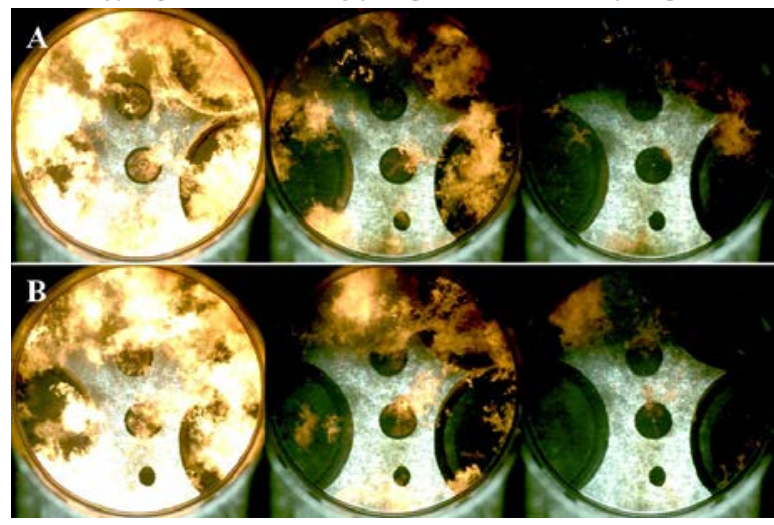

Fig. 17 Comparison of combustion processes of cases A and B ((a): apparent heat release rate and (b): combustion image)

retarded. This can account for the lower thermal efficiency.

Observations of the fuel spray and flame propagation were conducted using the optical engine to examine the effect of the split-main injection on the smoke emissions. The operating conditions are listed in table 4. Cases A and $\mathrm{B}$ have the same injection dwell $\left(1^{\circ} \mathrm{CA}\right)$ between the two main injections, but case $B$ has a smaller $2^{\text {nd }}$ main injection. The two main injections overlap the case $\mathrm{C}$, in which the injection dwell is $-1{ }^{\circ} \mathrm{CA}$, with a smaller $2^{\text {nd }}$ main injection.

The apparent heat release rate $\mathrm{d} Q_{\mathrm{a}} / \mathrm{d} \theta$ and combustion images for cases $A$ and $B$ are shown in figure 17. The first stage of the main injection starts when the pilot flame from injector $\mathrm{F}$ gets close to injector $\mathrm{R}$. Thus, the first main injection entrains the pilot flame and

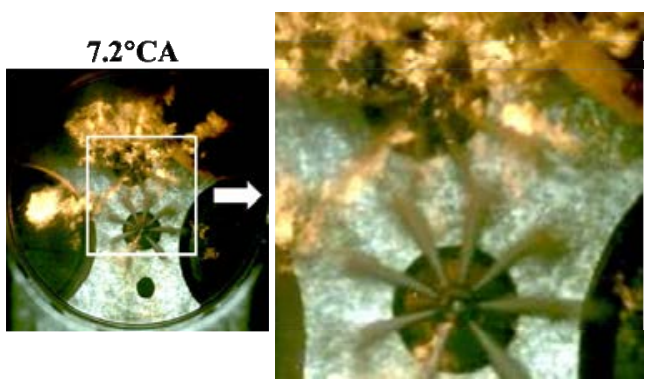

Fig. 18 Image for spray-spray impingement of case C
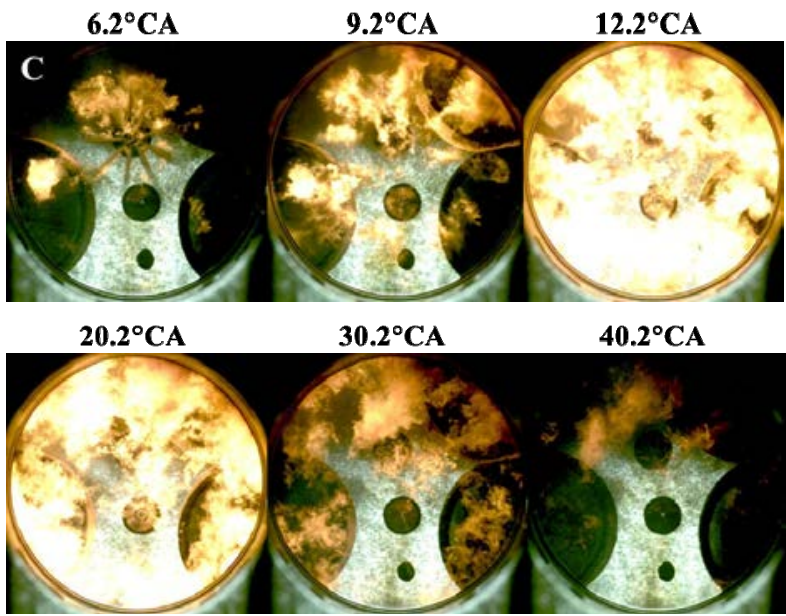

Fig. 19 Combustion images of case C

ignites after a short ignition delay $\left(6.2^{\circ} \mathrm{CA}\right)$. Then, the second main spray is injected into the main flame $\left(9.2{ }^{\circ} \mathrm{CA}\right)$. When the injection quantity of the second main injection is large (case A), the fuel quantity injected into the burnt gas increases, which would lead higher smoke emissions of the cases of split-injection.

When the two main injections overlap (case $\mathrm{C}$ ), the second main injection starts before the end of the first main injection, and the sprays injected at each stage interfere with each other, as shown in figure 18. Figure 19 shows image sequences for case $\mathrm{C}$. The luminous flame obviously lasts longer than in any other case in figure 17. Hence, it can be assumed that the fuel rich mixture increased in case $\mathrm{C}$ as a result of the reduced air entrainment caused by the spray-to-spray interaction.

\section{CONCLUSIONS}

To confirm the feasibility of using a variable injection rate in a small diesel engine, an experimental study was carried out using a single-cylinder diesel engine with an $85 \mathrm{~mm}$ bore equipped with two common-rail injection systems (DIS). The following conclusions were derived from experiments on the engine performance and emission characteristics with different injection pressures, dwells, and quantities for each injection stage.

1. Smoke emissions can be reduced using different injectors for the pilot and main injections in DIS, although the smoke level is higher than that of center injection under the same injection strategy. 
The Ninth International Conference on Modeling and Diagnostics for Advanced Engine Systems (COMODIA 2017), July 25-28, 2017, Okayama, Japan

2. The CO concentration increases when the pilot injection pressure is increased. However, when only the main injection pressure is increased, a smoke emission reduction is achieved without increasing the $\mathrm{CO}$ emissions.

3. Splitting the main injection with a low injection pressure reduces the injection rate and thermal efficiency compared with the case of a single main injection. However, when the injection pressure is increased so that the injection rate is comparable, the thermal efficiency exceeds that of the single-stage main injection case.

4. When splitting the main injection, a smaller injection quantity for second-stage injection decreases the smoke emissions compared to that for equally dividing the main injection.

5. In a case where the split-main injections overlap, the sprays injected at each stage interfere with each other, which causes a decrease in air entrainment and consequently an increase in smoke emissions.

\section{Acknowledgements}

The authors are grateful to Photron Limited for providing the high-speed camera. We would like to thank Masayoshi Furukawa for his valuable assistance with the experiment. This work was supported by the Council for Science, Technology and Innovation (CSTI), Cross-ministerial Strategic Innovation Promotion Program (SIP), "Innovative combustion technology" (funding agency: JST).

\section{REFERENCES}

[1] Suzuki, H., Minato, A., and Shimazaki, N., Trans. of JSAE, 43:4 (2012), p.863. (in Japanese)

[2] Tanabe, K., Kohketsu, S., and Nakayama, S., "Effect of Fuel Injection Rate Control on Reduction of Emissions and Fuel Consumption in a Heavy Duty DI Diesel Engine," SAE Technical Paper No. 2005-01-0907, 2005.

[3] Rottmann, M., Menne, C., Pischinger, S., Luckhchoura, V. et al., "Injection Rate Shaping Investigations on a Small-Bore DI Diesel Engine,” SAE Technical Paper 2009-01-0850, 2009.

[4] Kastner, O., Atzier, F., Rotondi, R., Weigand, A., and Wenziawski, K., Proc. THIESEL 2010, p.571

[5] Takeda, Y., Keiichi, N., and Keiichi, N., "Emission Characteristics of Premixed Lean Diesel Combustion with Extremely Early Staged Fuel Injection,” SAE Technical Paper 961163, 1996.

[6] Hashizume, T., Miyamoto, T., Hisashi, A., and Tsujimura, K., "Combustion and Emission Characteristics of Multiple Stage Diesel Combustion,” SAE Technical Paper 980505, 1998.

[7] Merkel, S., Eckert, P., Wagner, U., Velji, A. et al., SAE Int. J. Fuels Lubr., 1:1 (2009), p.1433.

[8] Okamoto, T., and Uchida, N., Trans. of JSAE, 47:3 (2016), p.717. (in Japanese)

[9] Fuyuto, T., Matsumoto, T., Hattori, Y., Kugimoto, K. et al., SAE Int. J. Fuels Lubr. 5:1 (2012), p.307.

[10] Osada, H., Aoyagi, Y., and Shimada, K., Trans. of
JSAE 43:4 (2012), p.855. (in Japanese)

[11] Sata, T., Ito, S., Kikusato, A., Kusaka, J., Daisho, Y. et al., Trans. of JSAE, 46:4 (2015), p.755. (in Japanese)

[12] Musculus, M.P.B., and Kattke, K., SAE Int. J. Engines, 2:1 (2009), p.1170. 